\title{
SQUARE FUNCTION ANALYSIS OF THE INDUCTOR-CONVERTER BRIDGE
}

by

Mehrdad Ehsani and Robert L. Kustom

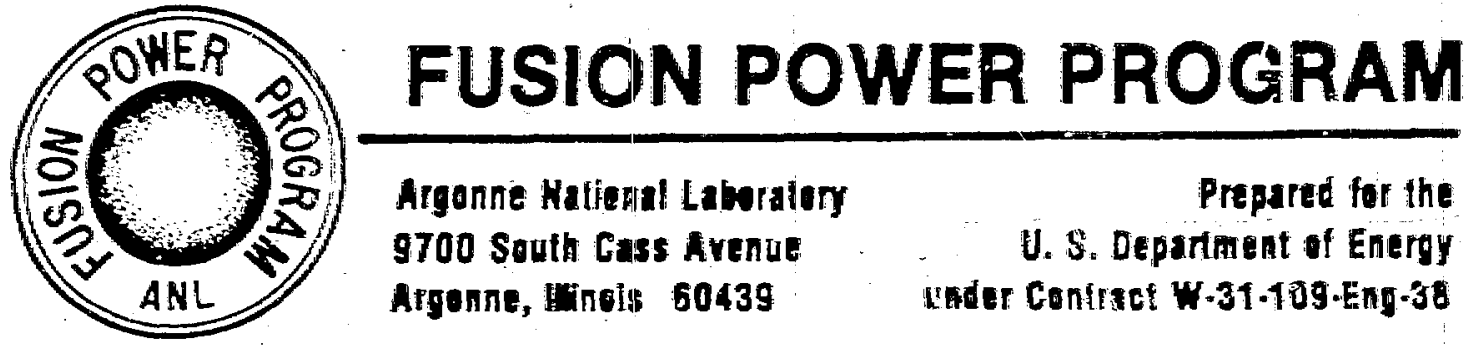


Distrituriton Categories:

Magmetic Fus iom Energy (UC-20)

Plasma Systens (ULC-200)

Magmetic Systems (UC-20b)

Fusion Systeras (UC-20d)

ANL/FPP/DM-118

ARGOMNE MATIOAAL LAMUATORE

9700 Sumith Cass Avemue

Argonne, IIIfmoís 60439

SQUARE FUMCTIOW AMAYSIS OF THE LDUCTOR-COAWERTER BAIDGE

by

Mehrdad Ehsani and Robert L. Kustom

Fusion Power Program

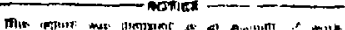

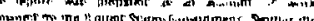

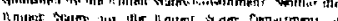

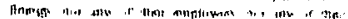

Irrace

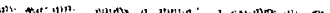

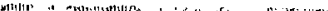

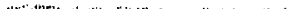

41,

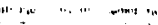

March 1979 
Tate of comates

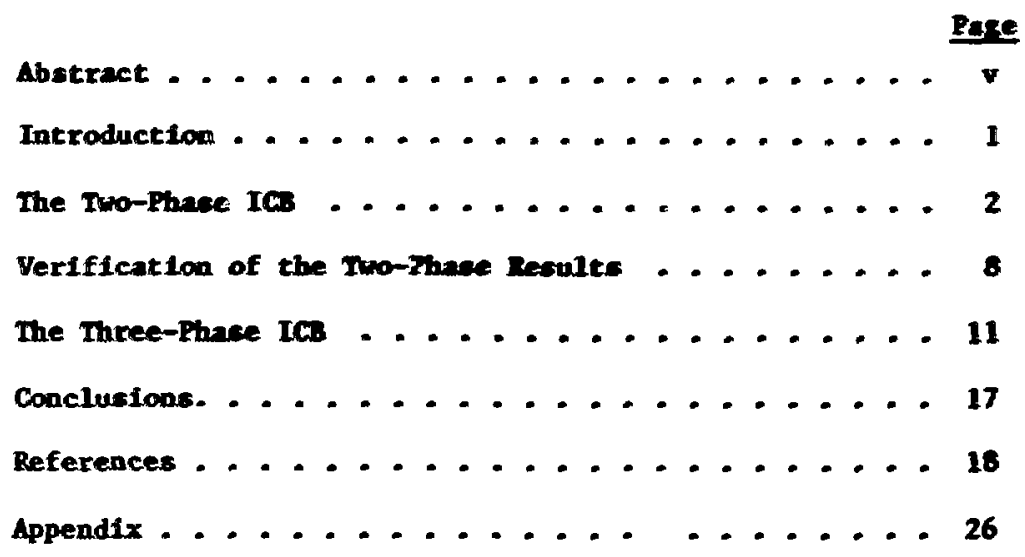




\section{LIST OF MGURS}

№.

Telle

Page

1 Circuit Digra for the 3-Capacitor Hodel IC Bridge . 19

2 Clrcult Diagram for the Tromphase ICB ......... 20

3 (a) $\operatorname{sq}\left(\gamma+\gamma_{0}\right)$, (b) $\operatorname{Ir}\left(\gamma+\gamma_{0}\right) \ldots \ldots 21$

4 One-Phase tquivalent C1resit of ICS ........ 22

5 (a) Ptace Current in a Truree-Phase ICB,

(b) Decomposition of the Phase Current Into Two Sq Functions ................. 23

6 The Per Phase Equivalent Circuft for the ThreePhase ICB .................... 24

7 The Average Power wo $r_{0}$ in Three-lhase ICB ....... 25 
squne Flimid AnLISIS or

THE INDUCTOR-COMVERER BRIDGE

by

Mehrdad thoani and Robert L. Kustom

\section{A.STINCT}

The transfer of energy between two superconducting colls can be controlled with an Inductor-Conwerter bridge (ICB) by chapging the relative tining between the storage side bridge and the load side bridge. The average voltages on the colls have ieen previously derired as a function of relative tining between the two balves of the bridges and the relative currents in the two colls using a one-11ne, harmonic current source represencation of each coll and its bridge network. Since the coll current in each of the ICR phases appears as bipolar rectangular pulses, an analysis based on unit step functions has been dereloped.

The unit step function analysis leads to sinple polynomal expressions relating the average coll poltages to relative tialng. The new derivatione are show to have the sane harmonic reprecentation as previously develofed. The polynonial expresstons are wore compatible to microprocessor control than are the harmonic function expresstons. 


\section{Introduction}

The Inductor-Conwerter Bridge (ICB) Is a DC-AC-DC converter, wth solld state witching elewents, for reversible energy tranfer from a storage Inductor to a laad inductor. A circuit digran is show In Fig- 1 . Conduction of current is commtated between thyristors at fixed Intervals following the normel inwerter sequence of $15,16,26,24,34$, and 35 . The active controllability of the rate of energy transfer renders these circulte espectally sultable for lnductive lands requiring randon power or current levels. One such application is in the egnetic field colls of the tokamk fusfon devices.

The detalls of operation and the characteristics of the ICs circuits have been reported in previous publications. 1,2 for the purposes of this report, It is sufficient to Indicate that the direction and the level of power flow 1 s deternined by the relative tining between the source and the losd bridge sutching cycles.

An analytical wethod for deriving the average loed power flow as a function of the relative bridge phase differesces and curreats in the colls has been presented in a sillax report. ${ }^{3}$ This wethod was based on the Jourfex components of the fundamental squere warome of ICs circults. The resules were in the form

$$
\langle p\rangle=\sum_{n=1}^{\infty} f_{n}(\alpha)
$$

where $\alpha$ is the tine-phace dffference between the two bridges and the functions $f_{n}(a)$ represent the Fourier comonents. The open form of this revult nkes the solution of $a$ In terns of $\langle p\rangle$ tedious and time conoung, particulariy in a computer algorith for real tine control.

This report presents the results of porer calculation usins specially tallored functions that are based on atep functions ambollzed by $5 q(x)$ and Ir (x) representation. These waveforn, which are inberent in the operation of ICB circuits, are used to formilate the arerage power equation in closed fore. Therefore, the exact evaluation of $\langle p\rangle$ in terw of $a$, and a seple Inverse solution of a in terns of $\langle p\rangle$. Is ande poselble. 
For verification, the new results are expanded in thetr Fourler components over the interval of interest to reproduce the previousiy reported results.

The Two-Phase ICB

To 111 ustrate the use of the $\mathrm{Sq}$ and $\mathrm{Tr}$ functions, the average power flow will be calculated for a twophase ICB. This elrcuit is the siplest ICB configuration and can be shom to be physically realizable. A circuit diagran Is shown In Fig. 2. The graphical form of the Sq and Tr functions is show In Fig. 3. The Sq function can be analytically reproduced by the sum of unit step functions. They for a good mothemetical representation of the currents $i_{1}(t)$ and $i_{2}(t)$. The Ir functions are the integrated form of $S q$ and are good representations of the capacitor voltege. A complete athemetical development of the Sq and $\mathrm{Ir}$ functions is presented in the Appendix.

It has been shown ${ }^{3}$ that an equivalent circuit for each phese of ICB can be represented by the diagran of F18. 4. Since two-1ine ac systen can be viewed either as two phase with respect to a reference or one phase ifne-toline, we have chosen the latter Interpretation for draing the equivalent circuit. Therefore, the calculated power from the equivalent cfrcuit wil be the total power of $\mathrm{HI}_{\mathrm{B}} \mathrm{2}$ as opposed to half power, which corresponds to one of the two phases.

The two current sources show in Pfg. 4 can be analytically described using the Sq functions described in the Appendix as follons:

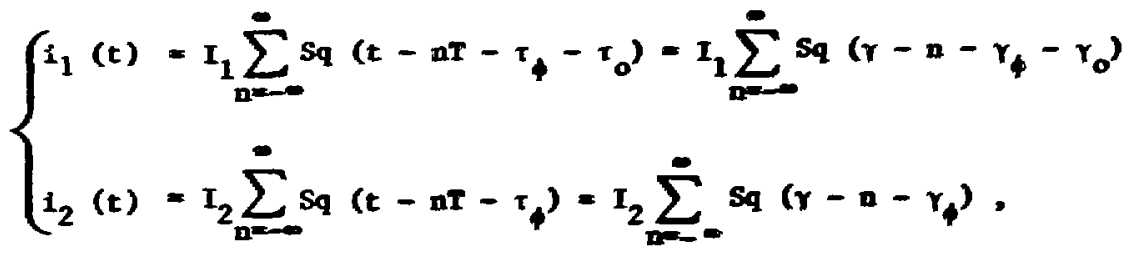

$$
\begin{aligned}
& -\infty<t<\infty, 0<\tau<T, 0<\gamma<1,0<\tau_{\phi}+\tau_{0}<T / 2,0<\gamma_{+}+\gamma_{0}<1 / 2^{*}
\end{aligned}
$$

Wote that for the case of $T / 2<\tau_{1}+T_{0}<T$ or $1 / 2<r_{t}+Y_{0}<1$, the Identity for $\left[T / 2-\left(\tau_{\phi}+\tau_{0}\right)\right]$ can je used, and the calculation vill proceed In a sifilar inner. 
In the above, $T_{1}$ and $r_{4}$ represent, respectively, the comon $t$ ine or phase delay of both $i_{1}$ and $t_{2}$ sources with respect to the reference tine, and $T_{0}$ and $r_{0}$ represent the relative cie difference or phase delay between $I_{1}$ and $1_{2}$

The capacitor voltage is

$$
\begin{aligned}
& v_{c}(t)=\frac{1}{c} \int_{0}^{t}\left(1_{1}+1_{2}\right) d t=\frac{1}{c} \int_{0}^{t} \sum_{n=-\infty}^{c} s q\left(\tau-n I-\tau_{1}-I_{0}\right) d \tau \\
& +\frac{I_{2}}{c} \int_{0}^{t} \sum_{n=-\infty} s q\left(\tau-n T-\tau_{\phi}\right) d \tau \\
& =\frac{1}{C} \sum_{n=1}^{\infty} \int_{0}^{t} s q\left(\tau-n I-\tau_{1}-\tau_{0}\right) d t \\
& +\frac{I_{2}}{c} \sum_{n=1}^{n} \int_{0}^{t} \operatorname{sq}\left(x-n T-\tau_{1}\right) d x \\
& =\frac{I_{1}}{C} \sum_{n=-}^{\infty} \operatorname{Ir}\left(t-n I-\tau_{1}-\tau_{0}\right)+\frac{I_{2}}{C} \sum_{n=m} \operatorname{Ir}\left(t-n T-T_{p}\right)
\end{aligned}
$$


The power delivered by the cource $f_{1}$ is

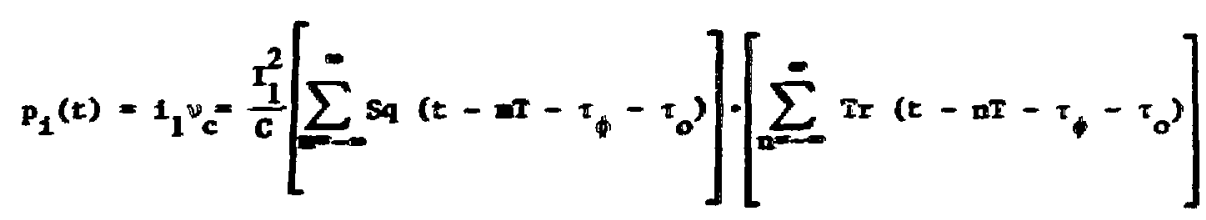

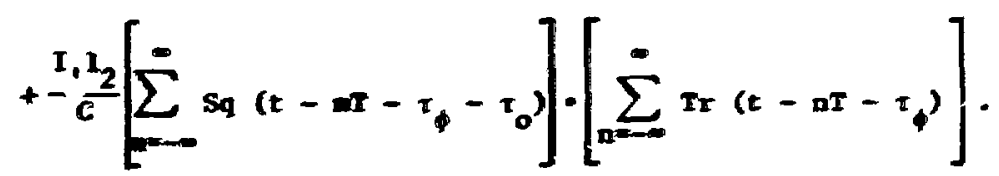

Ir the above, only the term in the wase location in time, sane period nubber, wil produce non-zero products. Therefore,

$$
\begin{aligned}
p_{1}(t)= & \frac{I_{1}^{2}}{c} \sum_{n=0}^{m} S q\left(t-n T-\tau_{\phi}-\tau_{0}\right) \cdot I r\left(t-n T-\tau_{\phi}-\tau_{0}\right) \\
& +\frac{I_{1} I_{2}}{C} \sum_{n=-\infty}^{\infty} S q\left(t-n T-\tau_{\phi}-\tau_{0}\right) \cdot \operatorname{Ir}\left(t-n T-\tau_{\phi}\right)
\end{aligned}
$$

The general forn of the average power dellwered by $i_{1}$ is

$$
\left\langle p_{1}\right\rangle=\frac{1}{T} \int_{p_{1} T+T_{1}}^{\left(n_{1}+1\right) T+T_{1}}
$$




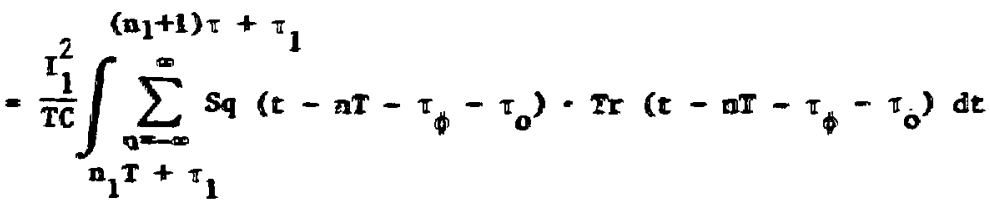

$$
\begin{aligned}
& +\frac{I_{1} I_{2}}{T C} \int_{n_{1} T+\tau_{i}}^{\left(n_{1}+1\right) T+I_{1}} \operatorname{Sq}\left(t-n T-n_{n}^{\infty}-\tau_{0} \cdot \pi r\left(t-n T-\tau_{0}\right) d t\right.
\end{aligned}
$$

Since the above Sq and Ir functions are periodic mith period $I$, the product Sq Ir is also periodic with period $T$. Therefore, the atove averaging integrals can be evaluated over any one period as follows:

$$
\begin{aligned}
& \left\langle p_{1}\right\rangle=\frac{I_{1}^{2}}{T C} \int_{n=\infty}^{T+\tau_{\phi}} \sum_{n}^{\infty} S q\left(\tau-n T-\tau_{\phi}-\tau_{0}\right) \cdot \operatorname{Tr}\left(\tau-n T-\tau_{\phi}-\tau_{0}\right) d \tau \\
& \text { T } \\
& +\frac{I_{1} I_{2}}{T C} \int_{\tau_{\phi}}^{T+\tau_{\phi}} \sum_{n=-\infty}^{\infty} S q\left(\tau-n T-\tau_{\phi}-\tau_{0}\right) \cdot T=\left(\tau-n T-\tau_{\phi}\right) d \tau
\end{aligned}
$$

To further simplify the integrals, ve will use a granslation cf exis of the kind $\tau=\tau^{*}+\tau$

$$
\left.{ }_{p_{1}}\right\rangle=\frac{I_{1}^{2}}{T C} \int_{0=-\infty}^{T} S q\left(\tau^{\prime}-n T-\tau_{0}\right) \cdot \operatorname{Tr}\left(\tau^{\prime}-n T-\tau_{0}\right) d \tau^{\prime}
$$

(Equation continued on following page) 


$$
\begin{aligned}
& +\frac{I_{1} I_{2}}{I C} \int_{0}^{T} \sum_{n=-\infty}^{I} s q\left(\tau^{\prime}-n I-\tau_{0}\right) \cdot T r\left(\tau^{\prime \prime}-n T\right) d \tau^{\prime} \\
& -\frac{I_{1}^{2}}{r C} \int_{0}^{T} \operatorname{sq}\left(\tau-\pi_{0}\right) \cdot \tau_{r}\left(\tau-\pi_{0}\right) d \tau \\
& +\frac{I_{1} I_{2}}{I C} \int_{0}^{T} \operatorname{sq}\left(\tau-\tau_{0}\right) \cdot \operatorname{Ir}(\tau) d \tau .
\end{aligned}
$$

We wil now pormalize the rarteble $t$ using the relationshfps $A-14, A-15$, and A-16 stren in the Appondlx:

$$
\begin{aligned}
& \left\langle p_{1}\right\rangle=\frac{r_{1}^{2}}{I C} \int^{1} \operatorname{sq}\left(r-r_{0}\right) \cdot(T) \operatorname{Tr}\left(r-r_{0}\right) d(r T) \\
& +\frac{I_{1} I_{2}}{I C} \int_{0}^{1} \operatorname{sq}\left(r-r_{0}\right) \cdot(T) \operatorname{Ir}(r) d(r I) \\
& \text { where } \quad Y=\frac{T}{T} \text { and } r_{0}=\frac{T_{0}}{I} \text {. }
\end{aligned}
$$




$$
\begin{aligned}
\left\langle p_{1}\right\rangle= & \frac{T_{1}^{2}}{C} \int_{0}^{1} \operatorname{sq}\left(\gamma-r_{0}\right) \cdot \operatorname{Ir}\left(r-\gamma_{0}\right) d r \\
& +\frac{\operatorname{II}_{1} I_{2}}{C} \int_{0}^{1} \operatorname{sq}\left(\gamma-\gamma_{0}\right) \cdot \operatorname{Tr}(r) d r .
\end{aligned}
$$

Using the identities of A-5 and A-6 of the Appendix, Eq. (10) can be transforned into

$$
\begin{aligned}
\left.{ }_{p_{1}}\right\rangle= & \frac{\mathrm{TI}_{1}^{2}}{C} \int_{0}^{1} S q\left[\gamma+\left(1 / 2-\gamma_{0}\right)\right] \cdot \mathrm{Ir}\left[\gamma+\left(1 / 2-\gamma_{0}\right)\right] d \gamma \\
& +\frac{\mathrm{II}_{1} I_{2}}{\mathrm{C}} \int_{0}^{1}-\mathrm{Sq}\left[\gamma+\left(1 / 2-\gamma_{0}\right)\right] \cdot \operatorname{Tr}(\gamma) d \gamma .
\end{aligned}
$$

Now using the integral relations, Egs. (A-7), (A-8), and (A-9) of the hppeadix with $r_{1}=r_{2}=\left(1 / 2-r_{0}\right)$ for the f1rst integrel and $r_{1}=\left(1 / 2-r_{0}\right), r_{2}=0$ for the second integral, we will get,

$$
\left\langle p_{1}\right\rangle=0-\frac{T I_{1} I_{2}}{C}\left[2\left(1 / 2-\gamma_{0}\right)^{2}-1 / 2+r_{0}\right]
$$


Hote that there is no net power from the fateraction of $I_{1}$ and the capacttor voltage due to $1_{1}$ - fact physically obvious. Therefore, the net power delivered by $1_{1}$ is doe to the interacion of $1_{1}$ and the capacitor roltage generated by $1_{2}$ only. The final result wy be simplified and presented in several form:

$$
\begin{aligned}
\left\langle p_{1}\right\rangle & =\frac{I_{1} I_{2}}{C}\left(r_{0}-2 r_{0}^{2}\right)=\frac{I_{1} I_{2}}{C}\left(\frac{t_{0}}{T}-\frac{2 t_{0}^{2}}{T^{2}}\right) \\
& =\frac{I_{1} I_{2}}{T C}\left(T t_{0}-2 t_{0}^{2}\right)=\frac{I_{1} I_{2}}{a c}\left(a-\frac{a^{2}}{\pi}\right) .
\end{aligned}
$$

In the above, $Y_{0}$ ts the tiding difference between $I_{1}$ and $i_{2}$ in fractions of the unity period; $t_{0}$ is the tining difference between $i_{1}$ and $i_{2}$ in seconds; $a$ 1s the phase difference between $1_{1}$ and $I_{2}$ in radians where che period is $2 \pi$ radians and is the angular frequency of $1_{1}$ and $1_{2}$. The radian units are given for comparison wh the results from Foorter analjats and have no real relation to the preseut analysis other then interpreting the square functions by trigonometric terminolosy.

\section{Verification of the To-thase Besulte}

The arerage poiter flow from one inductor to anotber using Fourter analyets ${ }^{3}$ is stwen by

$$
P_{1}{ }_{T}=\sum_{n=1}^{\infty} \frac{4 I_{1} I_{2}}{n^{3}{ }^{2} \omega}\left[1-(-1)^{n_{1}}\right] \sin n \alpha
$$

were $I_{1}$ and $I_{2} I_{s}$ the instentancous current in the cource and load inductor, respectively; is the angular frequency of bridge operation, $C$ is the lineto-1ine capacitance, and o is the phase angle in radians by which the load 
bridge leads the source bridge. The same srerage power calculated by square function analysis and expressed in radians was seen to be

$$
s_{1} s_{s q}=\frac{I_{1} I_{2}}{\omega C}\left(a-\frac{a^{2}}{m}\right)
$$

Comparison of the two form shows that for the power to be 1dentical, we mist have

$$
\sum_{n=1}^{\infty} \frac{4}{n^{3} \pi^{2}}\left[1-(-1)^{n}\right] \sin n a \frac{2}{2} a-\frac{a^{2}}{\pi} .
$$

Expanding the right-hand side of Bq. (16) in Ite Foorier cine series in the interwal $(0, m) *$ gives

$$
a-\frac{a^{2}}{n}=\sum_{n=1}^{\infty} b_{n} \sin n a \text {. }
$$

The values of the constants $b_{n}$ are

$$
b_{n}=\frac{2}{\pi} \int_{0}^{\pi}\left(a-\frac{a^{2}}{T}\right) \sin n \alpha d a
$$

(Bquation continaed on following page) 


$$
\begin{aligned}
& =\frac{2}{\pi}\left[\frac{1}{n^{2}} \sin n-\frac{a}{n} \cos n-\frac{1}{\pi}\left(\frac{2 a}{2} \sin n a\right.\right. \\
& \left.\left.-\frac{n^{2} \alpha^{2}-2}{n^{3}} \cos n \pi\right)\right]_{0}^{\pi} \\
& =\frac{2}{\pi}\left[\frac{1}{n^{2}} \sin n \pi-\frac{\pi}{n} \cos n-\frac{2}{n^{2}} \sin n \pi\right. \\
& \left.+\frac{n^{2} n^{2}-2}{n^{3} \pi} \cos m+\frac{2}{n^{3} \pi}\right] \text {. } \\
& =\frac{2}{\pi}\left[-\frac{\pi}{n} \cos \mathrm{n} \pi \frac{\pi}{\mathrm{n}} \cos \mathrm{n} \pi-\frac{2}{\mathrm{n}^{3} \pi} \cos \mathrm{n} \pi+\frac{2}{\mathrm{n}^{3} \pi}\right] \\
& =\frac{4}{n^{3} \pi^{2}}(1-\cos n \pi)=\frac{4}{n^{3} \pi^{4}}\left[1-(-1)^{n}\right] .
\end{aligned}
$$

Therefore,

$$
\alpha-\frac{a^{2}}{\pi}-\sum_{n=1}^{\infty} \frac{4}{m^{3} a^{2}}\left[1-(-1)^{2}\right] \operatorname{ain} n \alpha
$$

which is the equality needed to prowe the equimalence of Fourter and square function analyses. 


\section{The Three-Phase ICD.}

It has been shown ${ }^{3}$ thet the average power flow in the threephese ICs my be calculated from the one-phase equivalent eircoit. The total power to three tines that of one efrcuit. It is poratble to sbow that a three-phese ICB is the superposition of two of ple equivalent circeits of the rind used for the tro-phase ICB.

Figure 5(a) shows a typical waveform for a current in oae of the 3-1C: phase eqivalent circuits. Figure $S(b)$ shows the decomposition of this waveform into two Sq functions of appropriate phase difference. Fron this: illustration, it is evident that the source and hoad current waveform, respectively, can be shown as follows,

$$
\left\{\begin{aligned}
1_{1}(t)= & \frac{I_{1}}{2} \sum_{n=-\infty}^{\infty}\left[\operatorname{sq}\left(\tau-n T+\frac{T}{6}-\tau_{t}-\tau_{0}\right)\right. \\
& \left.+5 q\left(\tau-n T-\tau_{\phi}-\tau_{0}\right)\right] \\
I_{2}(t)= & \frac{I_{2}}{2} \sum_{n=-\infty}^{\infty}\left[\operatorname{sq}\left(\tau-n T+\frac{T}{6}-\tau_{\phi}\right)+\operatorname{sq}\left(\tau-n T-\tau_{\phi}\right)\right]
\end{aligned}\right.
$$

Siatlar argunents can be ade for the reduction of Eq.(20) as was in the 2-4 case for the average power calculation. Thes, with the anmation and ellainated, Eq. (20) becomea 


$$
\left\{\begin{array}{l}
f_{1}(t)=\frac{I_{1}}{2}\left[\operatorname{sq}\left(\tau+\frac{T}{6}-\tau_{0}\right)+\operatorname{sq}\left(\tau-\tau_{0}\right)\right] \\
f_{2}(t)=\frac{I_{2}}{2}\left[\operatorname{sq}\left(\tau+\frac{T}{6}\right)+\operatorname{sq}(\tau)\right], \\
0 \leq t \leq T, 0 \leq \pi \leq T, 0 \leq \tau_{0} \leq \frac{1}{2} .
\end{array}\right.
$$

Again, as In the $2-1$ case, it can be show that for arerage porer delivered by $i_{1}$, only $v_{2}$ due to $i_{2}$ need be calculated:

$$
\begin{aligned}
v_{2}(t) & =\frac{1}{C} \int_{0}^{t} 1_{2} d \tau=\frac{I_{2}}{2 C} \int_{0}^{t}\left[\operatorname{sq}\left(\tau+\frac{T}{6}\right)+\operatorname{sq}(\tau)\right] d \tau \\
& =\frac{I_{2}}{2 C}\left[\operatorname{Tr}\left(\tau+\frac{T}{6}\right)+\operatorname{Tr}(t)\right] .
\end{aligned}
$$

The power due to the interaction of $1_{1}$ and $r_{2} *$ is

$$
\begin{aligned}
P_{12}(t)= & I_{1} v_{2}=\frac{I_{1} I_{2}}{4 C}\left[\operatorname{sq}\left(\tau+\frac{T}{6}-\tau_{0}\right) \cdot \operatorname{Tr}\left(\tau+\frac{T}{6}\right)\right. \\
& +S_{q}\left(\tau+\frac{T}{6}-\tau_{0}\right) \cdot \operatorname{Ir}(\tau)+\operatorname{sq}\left(\tau-\tau_{0}\right) \cdot \operatorname{Ir}\left(\tau+\frac{T}{6}\right) \\
& \left.+S_{4}\left(\tau-\tau_{0}\right) \cdot \operatorname{Ir}(\tau)\right] .
\end{aligned}
$$


$-13-$

The average power dellwered by $i_{1}$ is

$$
\begin{aligned}
& \left\langle p_{12}\right\rangle=\left\langle p_{1}\right\rangle=\frac{1}{T} \int_{0}^{T} t_{1} v_{2} d t \\
& -\frac{I_{1} I_{2}}{4 \pi C} \int_{0}^{T}\left[S q\left(x+\frac{T}{6}-t_{0}\right) \cdot \operatorname{Ir}\left(\tau+\frac{T}{6}\right)\right. \\
& +\operatorname{Sq}\left(\tau+\frac{T}{6}-\tau_{0}\right) \cdot \operatorname{Ir}(\tau) \\
& +\operatorname{sq}\left(x-x_{j}\right) \cdot \operatorname{Tr}\left(x+\frac{T}{6}\right) \\
& \left.+\operatorname{Sq}\left(\tau-\tau_{0}\right) \cdot \operatorname{Ir}(\tau)\right] d \tau
\end{aligned}
$$

Using Eqs. $(A-14),(A-15)$, and $(A-16)$ of the Appendix, Eq. (23) becosis:

$$
\begin{aligned}
\left\langle P_{1}\right\rangle= & \frac{T_{1} T_{2}}{4 C}\left[\int_{0}^{1} s q_{q}\left(r+\frac{1}{6}-r_{0}\right) \cdot \operatorname{Tr}\left(r+\frac{1}{6}\right) d r\right. \\
& +\int_{0}^{1} s q\left(r+\frac{1}{6}-r_{0}\right) \cdot \operatorname{Tr}(r) d r
\end{aligned}
$$

(Iquation continued on folloring pege) 


$$
\begin{aligned}
& +\int_{0}^{1} \operatorname{sq}\left(r-r_{0}\right) \cdot \operatorname{Ir}\left(r+\frac{1}{6}\right) d r \\
& \left.+\int_{0}^{1} \operatorname{sq}\left(r-r_{0}\right) \cdot \operatorname{Ir}(r) d r\right] \\
& \Delta\left\langle p_{1}\right\rangle_{1}+\left\langle p_{1}\right\rangle_{2}+\left\langle p_{1}\right\rangle_{3}+\left\langle p_{1}\right\rangle_{4}
\end{aligned}
$$

Each of the above average posser components is ofillar to a 2- $\phi$ average power calculation as performed previously. The four composents will be calculated separately and the results wlll be cumed to calculate the total power:

$$
\left\langle p_{1}\right\rangle_{1}=\frac{T I_{1} I_{2}}{4 C} \int_{0}^{1} \operatorname{sq}\left(r+\frac{1}{6}-r_{0}\right) \cdot \operatorname{Tr}\left(r+\frac{1}{6}\right) d r
$$

It was denonstrated in the transformtion from Eq. (8) to Eq. (9) thet a common phase shift in the two currents with respect to the reference does not contribute to the average poster. Therefore, the integration of $\left\langle p_{1}\right\rangle_{1}$ is accomplished by Eq. $(A-8)$ of the Appendix, noting that $\gamma_{2}$ is zero and that $\left(1 / 2-\gamma_{1}\right)$ is equal to $1 / 2-\gamma_{0^{2}}$ quantity always grenter than zero.

$$
\begin{aligned}
\left\langle P_{1}\right\rangle & =\frac{I I_{1} I_{2}}{4 C} \int_{0}^{1} \operatorname{sq}\left(\gamma-r_{0}\right) \cdot \operatorname{Ir}(\gamma) d \gamma, \\
& =\frac{I I_{1} I_{2}}{4 C}\left(r_{0}-2 \gamma_{0}^{2}\right) .
\end{aligned}
$$


Likewise, the Integration of ${P_{1}}_{4}$ is accomplished by Eq. (A-8) of the Appendix; 1.e.,

$$
\begin{aligned}
\left\langle p_{1}\right\rangle_{4} & =\frac{T I_{1} I_{2}}{4 C} \int_{0}^{1} s q\left(r-r_{0}\right) \cdot T r(r) d r
\end{aligned}
$$

The integration for $\left\langle p_{1}\right\rangle_{2}$ is of the for

$$
\left\langle p_{1}\right\rangle_{2}=\frac{I_{1} I_{2}}{4 C} \int_{0}^{1} s q\left(r+\frac{1}{6}-r_{0}\right) \cdot \operatorname{Ir}(r) d r .
$$

The results of the Integration of Eq. (28) depend on whether $1 / 6$ - $y_{0}$ is greater than or less than zero. The polynomal in Eq. (A-4) provides a solution for $\mathrm{Eq}$. (28) when $0 \leq \gamma_{0} \leq 1 / 6$ wth the choice of $\gamma_{1}$ equal to $1 / 6-\gamma_{0}$ and $\gamma_{2}$ equal to zero. If $1 / 6 \leq \gamma_{0} \leq 1 / 2$, the polynomal of Eq. (A-8) gives the solution for Bq. (28). The reaults are:

$$
\left\langle P_{1}\right\rangle_{2}=\frac{T I_{1} I_{2}}{4 C}\left(2 \gamma_{0}^{2}+1 / 3 \gamma_{0}-1 / 9\right), \quad 0 \leq \gamma_{0} \leq 1 / 6
$$

and

$$
\left\langle P_{1}\right\rangle_{2}=\frac{T_{1} I_{2}}{4 C}\left(-2 \gamma_{0}^{2}+5 / 3 \gamma_{0}-2 / 9\right) . \quad 1 / 6 \leq \gamma_{0} \leq 1 / 2 .
$$


The equation for $\left\langle p_{1}\right\rangle_{3}$ is

$$
P_{1}>_{3}=\frac{I_{1} I_{2}}{4 C} \int_{0}^{1} s q\left(r-r_{0}\right) \cdot \operatorname{Ir}\left(r+\frac{1}{6}\right) d r .
$$

Equation (31) can be transfored by Eq. (A-5) of the Appendix Into

$$
\left\langle p_{1}\right\rangle_{3}=\frac{I_{1} I_{2}}{4 C} \int_{0}^{1}-s q\left[r+\left(\frac{1}{2}-r_{0}\right)\right]-\operatorname{Tr}\left(r+\frac{1}{6}\right) d \gamma
$$

Again, using the integration Equations $(A-7)$ and $(A-8)$ with $\gamma_{1}=\left(1 / 2-\gamma_{0}\right)$ and $r_{2}=1 / 6$, two solutions result:

$$
\left\langle p_{1}\right\rangle_{3}=\frac{T I_{1} I_{2}}{4 C}\left(-2 \gamma_{0}^{2}+\frac{1}{3} \gamma_{0}+\frac{1}{9}\right), \quad 0 \leq \gamma_{0} \leq 1 / 3
$$

and

$$
\left\langle p_{1}\right\rangle_{3}=\frac{I I_{1} I_{2}}{4 C}\left(2 \gamma_{0}^{2}-\frac{7}{3} \gamma_{0}+\frac{5}{9}\right), \quad 1 / 3 \leq \gamma_{0} \leq 1 / 2
$$

The total power in the circult is the sum of the four power components over three ranges of $\gamma_{0}$ since $\left\langle p_{1}\right\rangle_{2}$ and $\left\langle p_{1}\right\rangle_{3}$ are functionally different in these ranges:

$$
<p_{1}>=\left\{\begin{array}{l}
\frac{T I_{1} I_{2}}{C}\left(2 \gamma_{0}-3 \gamma_{0}^{2}\right), 0 \leq \gamma_{0} \leq \frac{1}{6} \\
\frac{T I_{1} I_{2}}{C}\left(3 \gamma_{0}-6 \gamma_{0}^{2}-\frac{1}{12}\right), \frac{1}{6} \leq \gamma_{0} \leq \frac{1}{3} \\
\frac{I I_{1} I_{2}}{C}\left(\gamma_{0}-3 \gamma_{0}^{2}+\frac{1}{4}\right), \frac{1}{3} \leq \gamma_{0} \leq \frac{1}{2}
\end{array}\right.
$$


The resultant value of $\left\langle p_{1}\right\rangle$ expresses in tbe Eqs. (35), (36), and (37) represents the closed form of the infinfte harmonfe ceries for 3-\$ ICW, obtalned from Pourier analysis. 3

Several interesting reasiks can be based on the preceding analysis:

1. The per phase equivelent circult for the 3-\$ ICB an be further deconposed as shoin in Fig. 6. From this figure it is evident that four cosponents of average power are at work. Depending on the size of $Y_{0}$, sone of these components $=y$ be negative.

2. The three cegaents of $\left\langle\mathrm{p}_{1}\right\rangle=\gamma_{0}$ curve are shown in F1s. 7 . At the points of interface, the curves connect soothly; 1.e., both the value and the slopes at the interface points atch.

3. In au argunent afilar to that given in the Fourter analysis, for ICB system with low frequency response in comprison to the bridge frequency, the net power wa be approxt nated by

$$
\left\langle p_{1}\right\rangle=\frac{I}{C} I_{1}(t) \cdot I_{2}(t) f\left(\gamma_{0}\right)
$$

where $I_{1}(t)$ and $I_{2}(t)$ are relatively slos (conpared to s sultching sequence) tine-varying inductor currente.

4. The $Y_{0}$ value for mximen net porer can be calculated fros differentiating the addie segnent of $\left\langle p_{1}\right\rangle$ we $\gamma_{0}$ curve. The result 1s $Y_{0} \max =1 / 4$ whteh corresponds to $90^{\circ}$ phese shift.

\section{Conclusions}

The celculations in this report illustrated sone of the applications of the square function nethod. This nethod anking ues of the rectengular (Sq) and triangular (Tr) weve apes ts wil suited to the ICl circuits, In a ofillar way that the teigonometric rules are used in the annigets of the circuits with simusidal weveoheses. The celeulations relate nore directly to the actual circult waveform and the complications of transforms the problea 
to a form usable by other techniques; e.8., Fourler technique, were elininated. Consequently, the results rere simpler and easier to interpret.

Purthermore, expressing the actual circult warefores analytically allow: other useful calculations such as actual capacitor roltages throughout the transfer cycle, the study of comutation throughout the cycle, and the actual coll voltazes and instantaneous currents.

The sipilcity of the functional dependence of the various circuit quantities should also help in the design process. This technique ny also prove useful in the frequency studies of the ICB circuits. The result: obtained by the square function nethod are of Ipler to use and nore efficient to implement in an active control algorith, especially, for afcroprocestur controllers where complex functional calculations are extrenely tine-consuning by comparison to sfeple witiplication and addition.

The calculation procedure uscd for the 3-\$ ICs denonstrates the method for any -phase ICB.

Finally, the 2- ICs presented in this report is not only iccelf a useful design candidate for energs trancfer, but also was shom to be the building black of the more compliceted ICB configurations.

\section{Reference:}

1. R. L. Kuston et al., "The Use of Hultiphese Inductor-Converter Bridges es Act1vely-Controlled Porer Supplies for Tokmak Colle," Argonne national Laboratory Report An/FPP/Mt-78 (April 11, 1977).

2. H. A. Peterson et a1., "Superconductive Indactor-Converter Unite for Pulsed Power Loads," Proceedinge of International Conference on Iners; Storage, Compression, and Sutching, Ast-Torino, Italy (Iovember 1974).

3. H. Ehsanf, R. L. Xustom, Mnnlysis of the Haltiphese Inductor-Comverter Bridge," Argone National Laboratory leport AL/TR/TH-114 (Auguat 1978 ). 


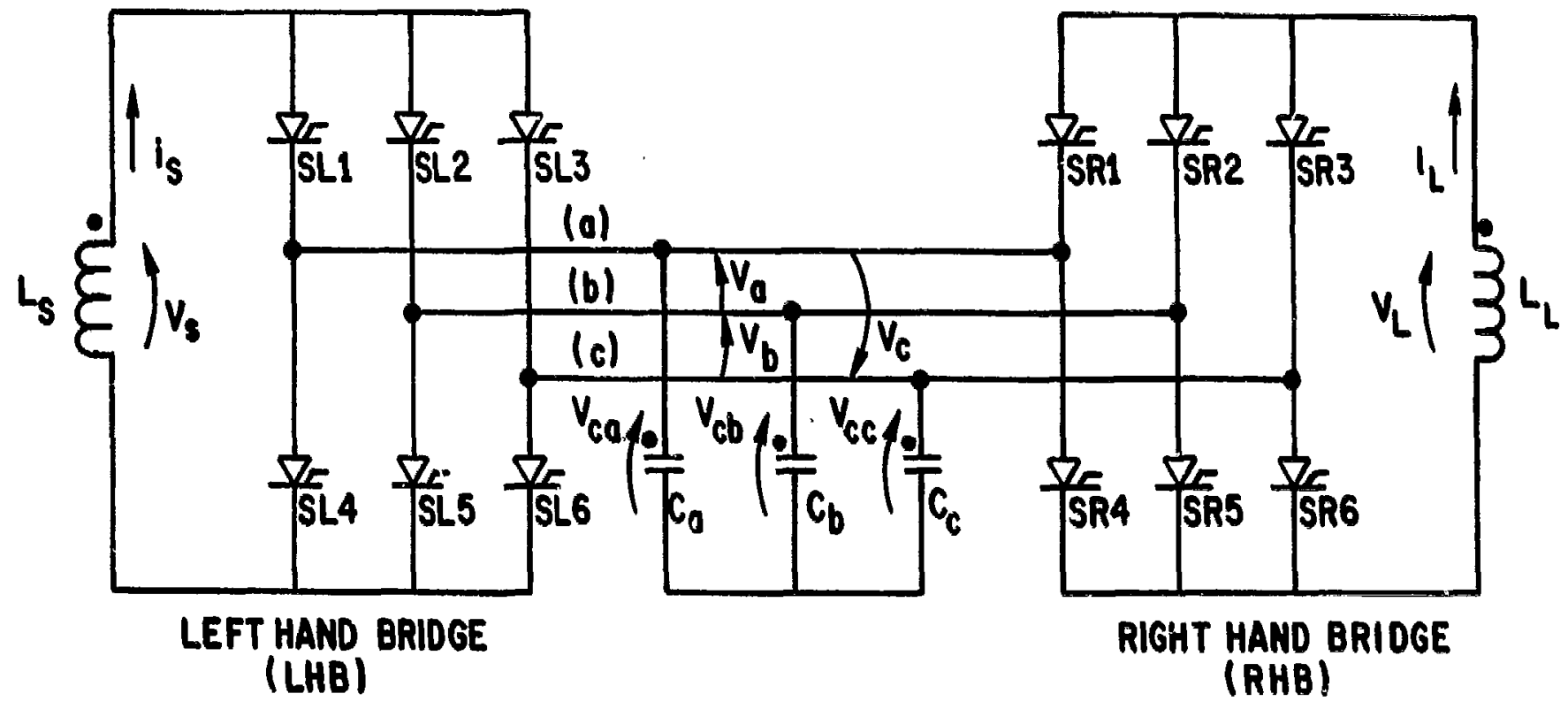

Fig. 1. Circuit Diagram for the 3-Capacitor Model IC Bridge. 


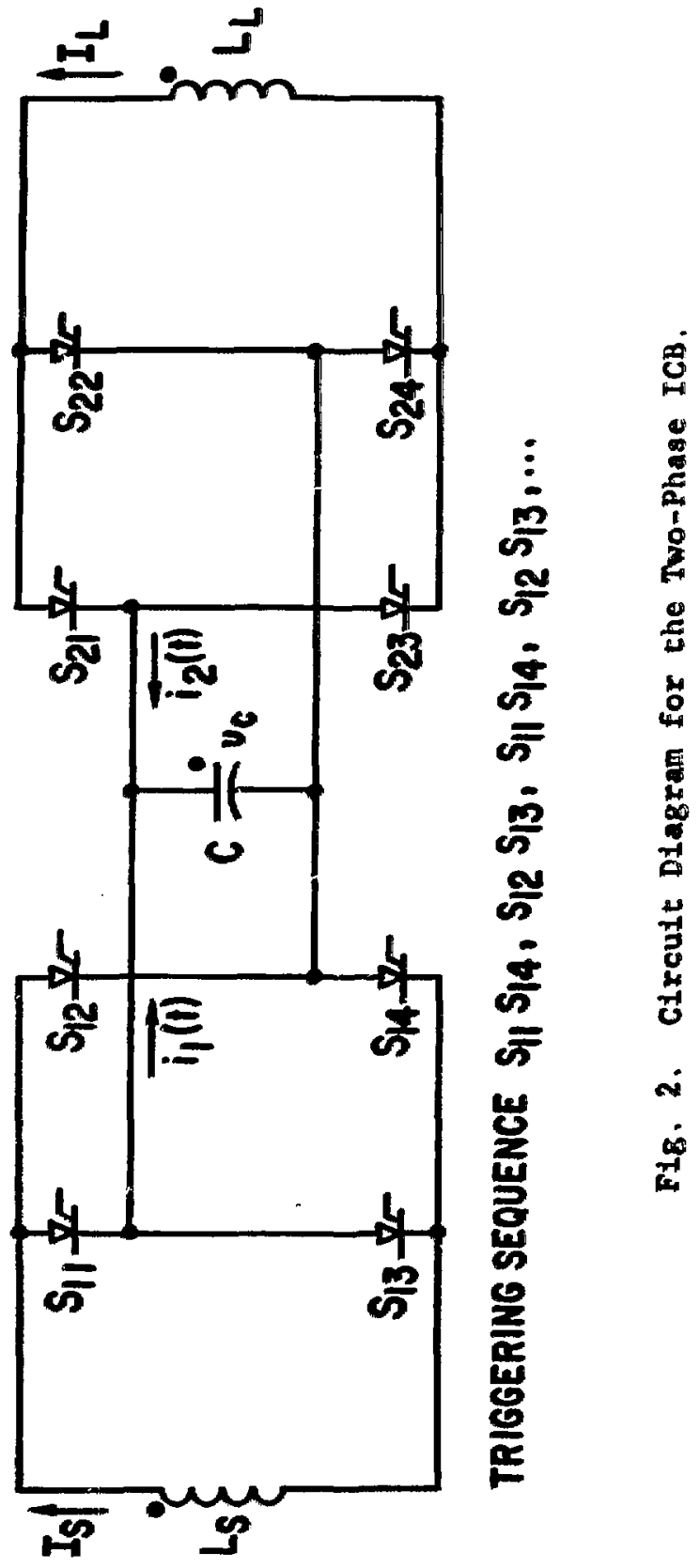




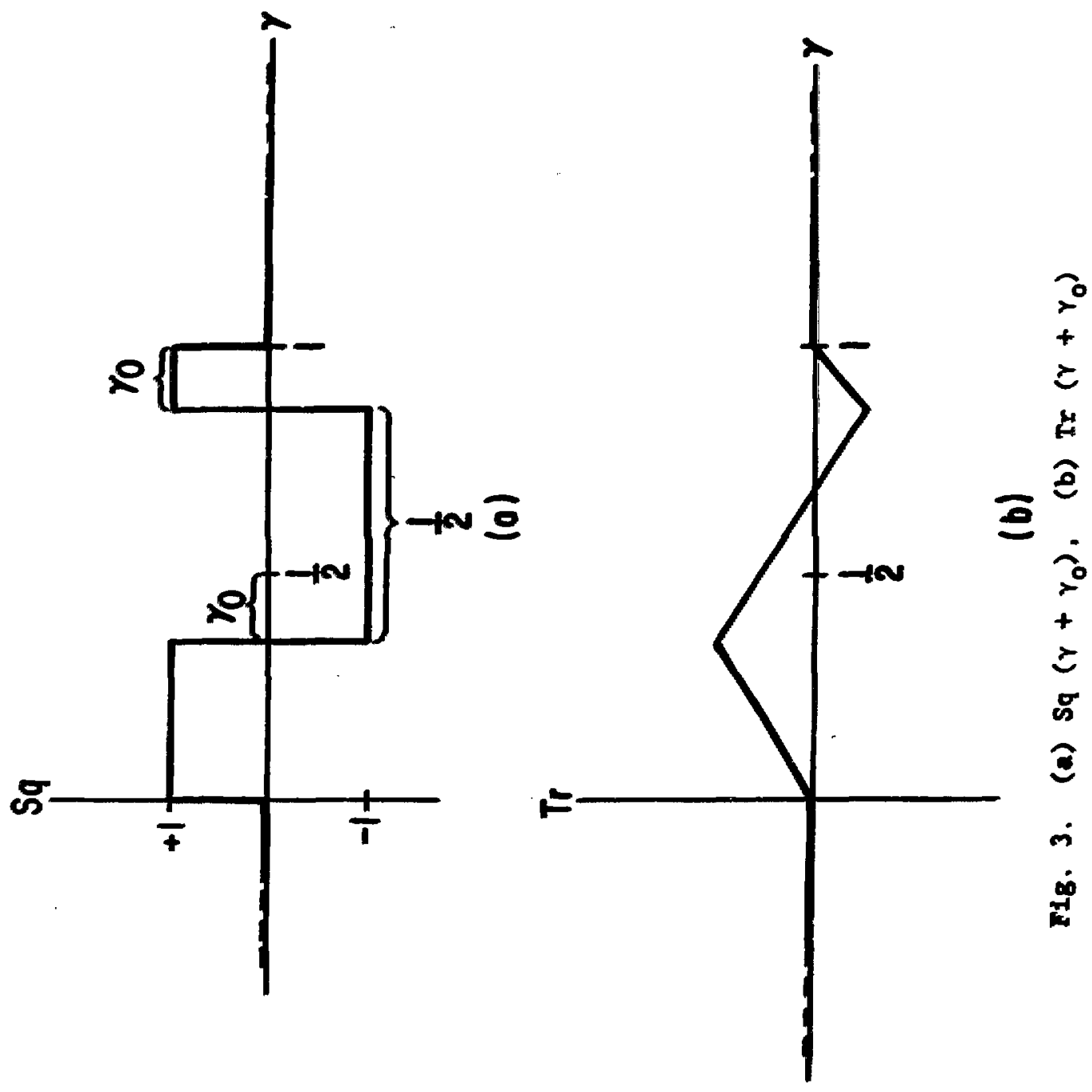




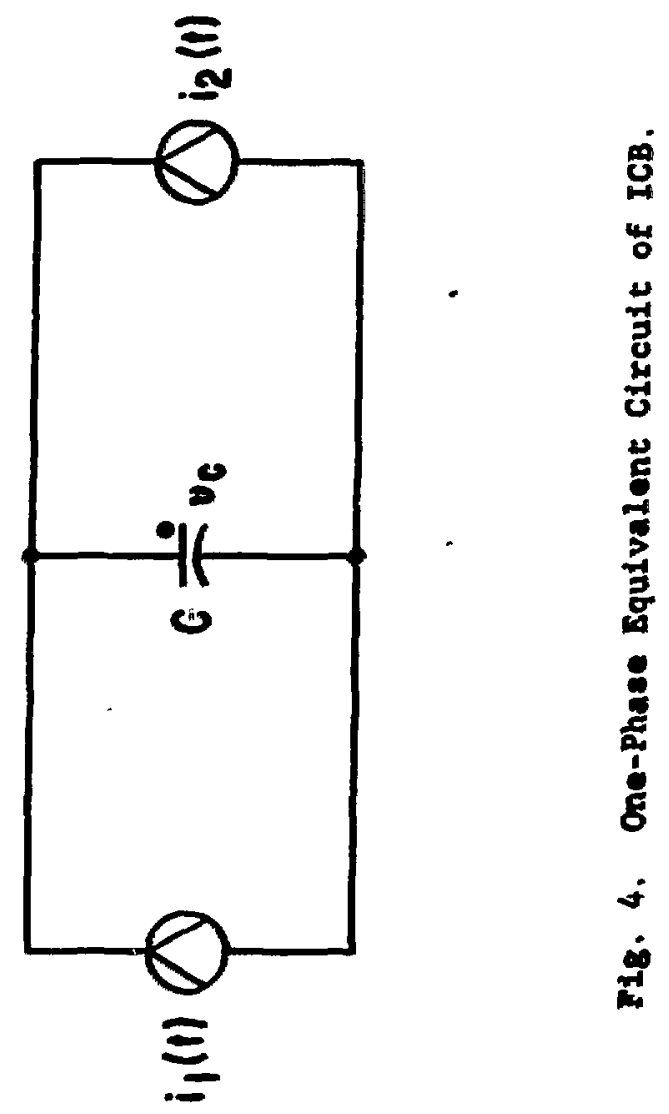



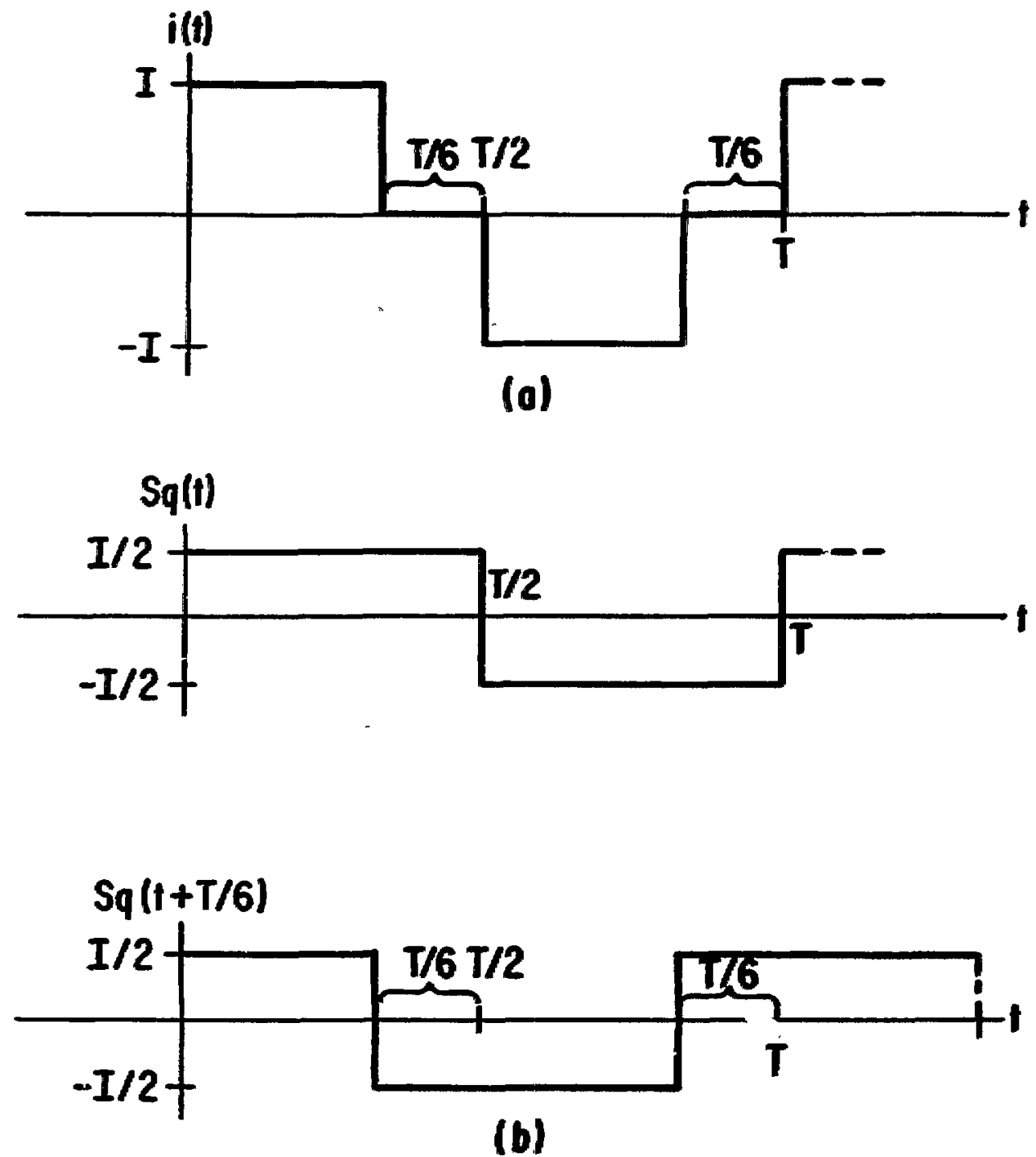

Fig. 5. (a) Phase Current in a Three-Phase ICB,

(b) Decomposition of the Phase Current into tiro Sq functions. 


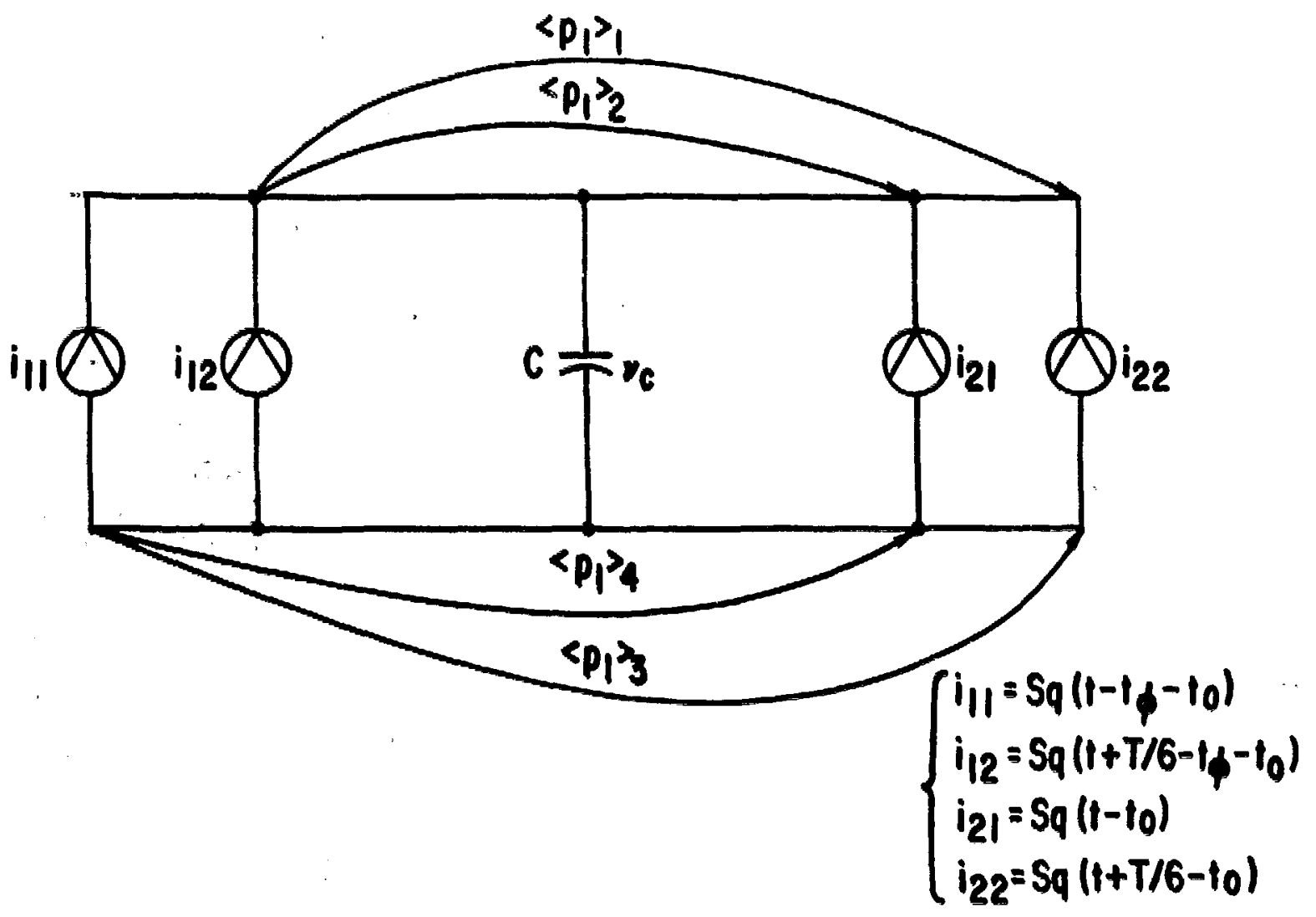

Fig. 6. The Per Phase Equivalent Circuit for the Three-Phase ICB. 


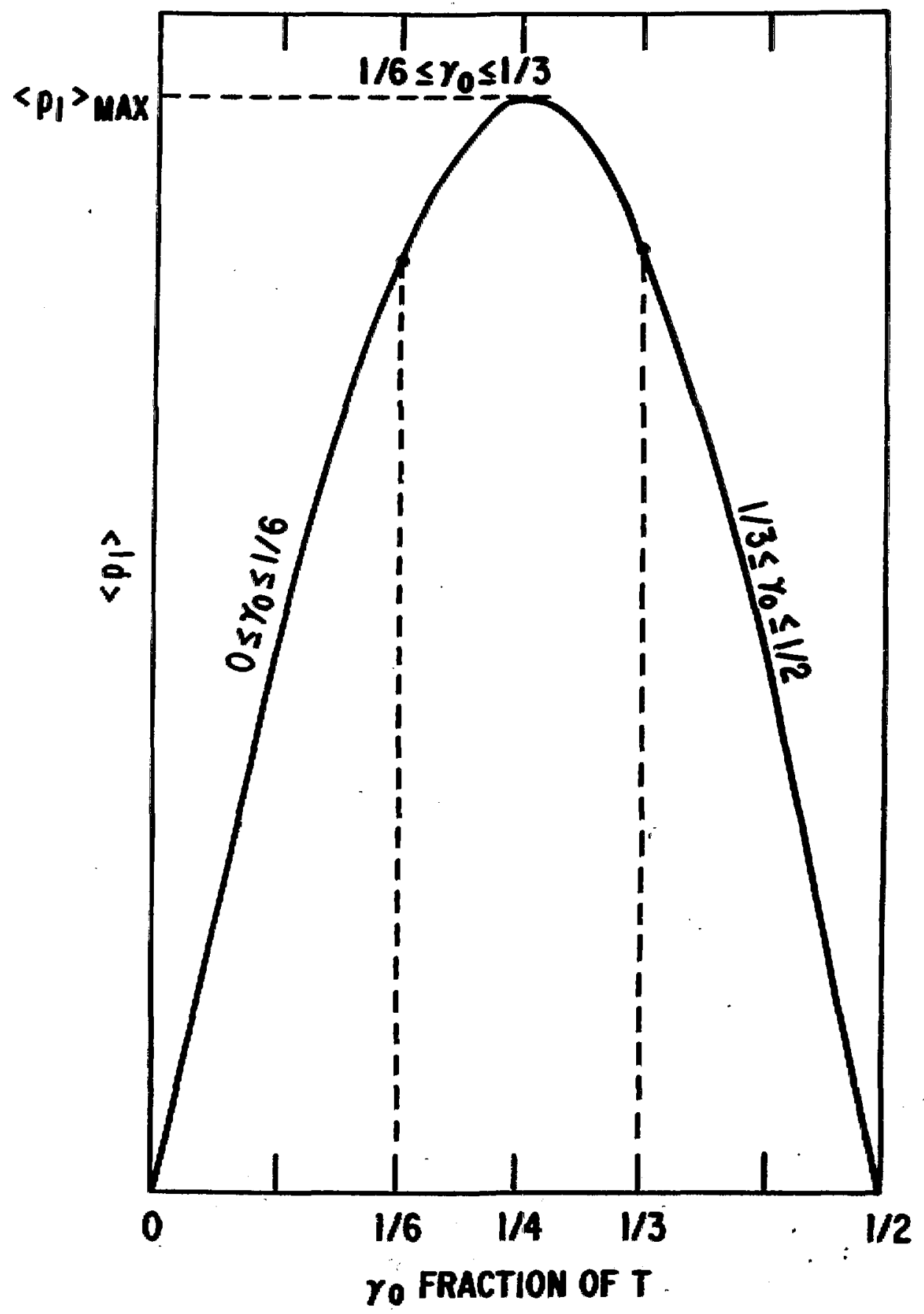

Fig. 7. The Average Poner vs $\gamma_{0}$ in Three-Phase ICB. 
APRDidT

The Sq and Tr Functions

The $S q$ functions are defined as the sum of unit ctep functions in the following anver:

$$
\begin{aligned}
& \text { Sq }\left(r+\gamma_{0}\right) \triangleq v(r)-2 v\left(\gamma-1 / 2+r_{0}\right) \\
& +2 v(\gamma-1+\gamma)-0\left(\gamma_{0}-1\right), \\
& 0 \leq r_{0} \leq \frac{1}{2}, 0<r \leq 1
\end{aligned}
$$

and $U(Y)$ is the unit step function. The Sq fonction show In FIg. 3a is analytically constructed by this expression. The first unte step function $U(Y)$ is zero for $Y$ less than $O$ and unity at zero and beyond. The second unft step function is zero for $Y<1 / 2-X_{0}$ and jueps to -2 when $Y>1 / 2-\gamma_{0}$. The sw of the first unt step function and the cecond unit function add together to give a net vilue of -1 for $r>1 / 2-r_{0}$. The third step function 18 zero for $Y<1-Y_{0}$; and so in this waner the andrefcal expression for the Sq is constructed.

The Ir functions are defined as the integral walve of the Sq functions: i.e.s

$$
\begin{aligned}
& \operatorname{Ir}\left(r+r_{0}\right) \Delta \int_{0}^{r} s q\left(\varepsilon+r_{0}\right) d \xi \\
& =\gamma U(\gamma)-2\left(Y-\frac{1}{2}+Y_{0}\right) U\left(Y-\frac{1}{2}+\gamma_{0}\right) \\
& +2\left(\gamma-1+\gamma_{0}\right) 0\left(Y-1+\gamma_{0}\right)-(\gamma-1) \mathrm{U}(Y-1)
\end{aligned}
$$


The first unit step function in Eq. (L-1) is zero until $Y \geq 0$; after which the function increases linearly wth $\gamma$. Lifcutes, the integal value of the second unit step function is zero unth $r=1 / 2-Y_{0}$ and afternards increased linearly with $Y$. The If functions shom in Fig. $3 b$ are analjtically reproduced by iq. $(\Delta-2)$.

The vilue of the product of an $S q$ and a Tr function integrated orer a $T$ toterval of 0 to 1 wil be extensively be ued in calculating the everage power flow in the circults of interest. Inerafore, the following relations are useful:

$$
\int_{0}^{1}\left[S q\left(r+r_{1}\right) \cdot T r\left(r+r_{2}\right)\right] d r=\left\{\begin{array}{c}
-2 r_{1}^{2}-r_{1}+4 r_{1} r_{2}+r_{2}-2 r_{2}^{2} \\
r_{1} \leq r_{2} \\
2 r_{1}^{2}-r_{1}-4 r_{1} r_{2}+r_{2}+2 r_{2}^{2}
\end{array}\right.
$$

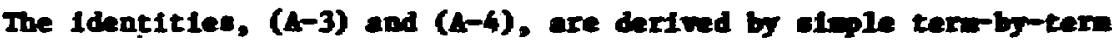
integration, taking account of the fect the integration has a mowrero contribution only after $Y$ exceed the larger of the two palues of $Y_{1}$ end $Y_{2}$. Note that for $\gamma_{1}=\gamma_{2}$, efther one of the abowe reaults will atwe 0 . Two folloring ldentities all also be of contarable value:

$$
\operatorname{sq}\left(\gamma-\gamma_{0}\right)=-\sin \left[\gamma+\left(\frac{1}{2}-\gamma_{0}\right)\right]
$$


$-28-$

and

$$
\operatorname{Ir}\left(\gamma-\gamma_{0}\right)=-\operatorname{Ir}\left[\gamma+\left(\frac{1}{2}-\gamma_{0}\right)\right], 0 \leq \gamma_{0} \leq \frac{1}{2} .
$$

$(A-6)$

These are easily verified by direct substitution. Note that by using the above identities, we can easily derive the operation for lagging functions from the operation for leading functions. For example,

$$
\begin{gathered}
\int_{0}^{1}\left[s q\left(r-r_{1}\right) \cdot \operatorname{Tr}\left(r+r_{2}\right)\right] d r \\
=-\int_{0}^{1}\left\{s q\left[r+\left(\frac{1}{2}-r_{1}\right)\right] \cdot \operatorname{Tr}\left(r+r_{2}\right)\right\} d r \\
-\left[-2\left(\frac{1}{2}-r_{1}\right)^{2}-\left(\frac{1}{2}-r_{1}\right)+4\left(\frac{1}{2}-r_{1}\right) r_{2}+r_{2}-2 r_{2}^{2}\right] \\
\left(\frac{1}{2}-r_{1}\right) r_{2} \\
-\left[2\left(\frac{1}{2}-r_{1}\right)^{2}-\left(\frac{1}{2}, 1\right)-4\left(\frac{1}{2}-r_{1}\right) r_{2}+r_{2}+2 r_{2}^{2}\right] \\
0,\left(\frac{1}{2}-r_{1}\right)=r_{2} \cdot \\
\left(\frac{1}{2}-r_{1}\right)>r_{2}
\end{gathered}
$$

$(1-7)$

$(A-8)$

$(\mathbf{a}-9)$ 
The Sq and Ir functions wy be generalized to periodfe fonctions untes an integer sumetion; 1.e.,

$$
\begin{aligned}
s q\left(r^{2}+r_{0}\right)=\sum_{n=1}^{-n}\left(r-r_{0}\right) \\
=\sum_{n=0}^{\infty}\left\{(r-n)-2 v\left(r-n-1 / 2+r_{0}\right)\right. \\
\left.+2 v\left(r-n-1+r_{0}\right)-v(r-n-1)\right\}
\end{aligned}
$$

and

$$
\begin{aligned}
& \operatorname{Tr}\left(\gamma^{\prime}+\gamma_{0}\right)=\sum_{n=\infty}^{\infty} \operatorname{Tr}\left(\gamma-n+\gamma_{0}\right) \\
& =\sum_{n=0}^{\infty}\left(\gamma-n+r_{0}\right) U\left(r-n+r_{0}\right) \\
& -2\left(Y-n-1 / 2+\gamma_{0}\right) \text { U }\left(Y-n-1 / 2+\gamma_{0}\right) \\
& +2\left(Y-n-1+Y_{0}\right) \tilde{n}\left(Y-n-1+Y_{0}\right) \\
& -\left(r-n-1+Y_{0}\right) v\left(\gamma-n-1+\gamma_{0}\right)
\end{aligned}
$$

where $-\infty<\gamma^{\prime}<0,0<Y<1$ and $\gamma^{\prime}=n+\gamma, n=0,1,2, \ldots \ldots$

Clearly, the Sq and Ir functione show in FIs. 3 are anelyticalls reproduced for any chotee of poeftive or peptive integer in lqe. $(4-10)$ and $(4-11)$. 
The perlod over which the Sq and Ir functione ere defined can be generallzed frow integer to arbitrary values for brosder applicetion. The Sq functions are basically independent of the nariable. So that,

$s q\left(t+t_{0}\right)=s q\left(r+\gamma_{0}\right) \cdot\left\{\begin{array}{c}0 \leq t \leq T, 0 \leq t \leq \frac{T}{2} \\ 0 \leq Y \leq 1,0 \leq \gamma_{0} \leq \frac{1}{2}\end{array}\right.$

and

$$
\operatorname{Tr}\left(t+t_{0}\right)=\int_{0}^{t} \text { sq }\left(\sigma+t_{0}\right) d \sigma,\left\{\begin{array}{l}
0 \leq t \leq T \\
0 \leq t_{0} \leq \frac{T}{2}
\end{array}\right.
$$

The variable, $t$, and the paraneter, $t_{0}$, for any arbitrary period of $T$ are related to $Y$ and $\gamma_{0}$ for the unity feriod by

$$
\begin{aligned}
& r=t / I \text { and } \\
& Y_{0}=t_{0} / T .
\end{aligned}
$$

Substitution of $t$ and $t_{0}$ in the integral Bq. $(4-13)$ readte in the followins

$$
\operatorname{Ir}\left(t+t_{0}\right)=I \int_{0}^{\gamma} \operatorname{sq}\left(E+\gamma_{0}\right) d E
$$


$-31-$

Therefore,

$$
\begin{aligned}
\operatorname{Tr}\left(t+t_{0}\right)= & \operatorname{T}\left[\operatorname{Ir}\left(Y+Y_{0}\right)\right]=t u(t)-2\left(t-\frac{T}{2}+t_{0}\right) u\left(t-\frac{T}{2}+t_{0}\right) \\
& +2\left(t-I+t_{0}\right) \cdot\left(t-I+t_{0}\right)-(t-I) u(t-T)
\end{aligned}
$$

$(4-17)$

For time base calculations, the Eds. ( $(4-12),(A-14),(A-15)$, and $(a-17)$ can be utilized. 